\title{
反復凍結法によるポリビニルアルコール ヒドロゲルの包括性
}

お茶の水女子大学家政学部

東京大学生産技術研究所
小川昭二郎・杉井 史子

関裕之・岩元 和敏・妹尾学

\section{INCLUSION PROPERTIES OF FREEZE-THAW POLYVINYL ALCOHOL HYDROGEL}

\author{
By Shojiro Ogawa*! Humiko Sugii*1, Hiroyuki Seki*2, Kazutoshi Iwamoto*2 and Manabu Seno ${ }^{* 2}$ \\ *1 (Faculty of Home Economics, Ochanomizu University) \\ *2 (Institute of Indusirial Science, The University of Tokyo)
}

\begin{abstract}
A solution of a mixture of polyvinyl alcohol (PVA) and polyethylene glycol (PEG) in water gave a PVA hydrogel including PEG by a given cycle of freezing and thawing. The rate of the release of PEG from the gel decreased with increasing the molecular weight of $P E G$ and the freezing cycle number. Diffusion coefficients of $P E G$ in the gel were determined by the relationship between the release amounts and square root of release time. Diffusion coefficient decreased with increasing the cycle number, then becoming horizontal after a definite number of cycle which depended on the molecular weight of PEG. We found that emulsified triolein was also included in the gel by the freezing and thawing method.
\end{abstract}

(Received February 23, 1989)

\section{1. 緒言}

生体組織に類似の物性を有する医用材料の出現が待望 されているが，その高含水性，柔軟性と機械的强度とは 雨立し難いときれてきた。これまでポリビニルアルコー ル (PVA) のゲル化の方法は数多く知られているが, 強靱なゲルを得ることが困難であった。近年，南部，渡 瀬らは，PVA 水溶液は凍結後解凍することにより粘着 性ゲルに転化されるが，この単純凍結ゲルは機械的強度 が少るのに対し，さらに凍結解凍を繰り返した反復凍結 PVAヒドロゲルは，含水率が70－90\%に及ぶにもかか わらず高い弾性率を示すことを見出しだ2)。ゲル化時 の動的粘弾性と応力緩和特性の経時変化, PVA 鎖上置 換基による立体障害，X線回折などの知見から，凍結過 程においてPVA 鎖絡み合い点に微結晶種が発生しこ れがわずかながら成長して若干の耐熱性を得，実質的網 目橋かけを具えた弾性体が生成したと推察されている。 また，走查型電子箕徎鏡によりゲルが潵細な多孔を持つ
ことも観察され，これはPVA/水の相分離が進行するこ とによるものと考えられている゙๋。以上のような基䃈的 な性質の研究の他, 包括薬郕の徐放性 ${ }^{4}$ ，バイオリアク ターとしての利用，医用材料への応用等が検討されてい るが応用的知見はまたあまり得られていない。

そこで, PVAヒドロゲル中に包括させた水溶性物質 およひ眯水性物質の放出速度を測定することによりゲル の物質包括性，安定性を検討し，応用的知胃を得ること を試みた。水溶性物質としては各種分子量のポリエチレ ングリコール（PEG），踈水性物質としてはトリオレイ ンを用いた。なお，オイルを包括させたヒドロゲルは乳 化状態をそのまま固定するという特異な形態であり，そ の安定性を检討した。

\section{2. 実佒}

\section{1 試 菜}

ポリヒニルアルコールは和光純薬工業の完全ケン化 PVA（重合度1500～1800；ケン化度 $\min .98 \mathrm{~mol} \%$ ），术 
リエチレングリコールは東京化成工業製（平均分子量 200及び3000）及び和光純薬工業製（平均分子量600, 1000，2000，7500及び20000）を用いた。ジブロモプロ バンは東京化成工業製，臭化水素及びトリオレインは和 光統薬工業製を用いた。

\subsection{PVA/PEG 系及び PVA ヒドロゲルの閑}

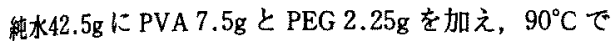
2時間加熟して溶解した。その後, 振とうしながら放冷 して室温にした。重量测定後, 注射器で $10 \mathrm{ml}$ 試料管に $4.5 \mathrm{~g}$ ずつ注入し，密閉した後パラフィルムで覆った。 (バラフイルムで覆うことにより，凍結時のガラス破損 を防ぐことが出来る。 これを冷凍庫（䄪 $-20^{\circ} \mathrm{C}$ ）で凍 結させた後融解させることを繰り返して PEG を含む PVA ヒドロゲルを調製した。また，同様の条件で PEG を含まないPVAヒドロゲルを得た。

\section{$2.3 \mathrm{PVA} /$ トリオレイン系乳化ヒドロゲルの摆㱔}

PVA 7.5g 純水 $42.5 \mathrm{~g}$ に溶解した水溶液を $4.5 \mathrm{~g}$ ずつ 武料管に注入した。これにトリオレイン $1.125 \mathrm{~g} を$ え, 爫化䔖置（BRANSON SONIFIER）により10分間乳 化した。の後, 密閉して反復凍結处理を行った。

\subsection{PVA/PEG 系ヒドロゲルからの PEG 放出実駼} 2.2て得た PVA $/ \mathrm{PHG}$ 系ヒドロゲルを $100 \mathrm{ml}$ 試料管に

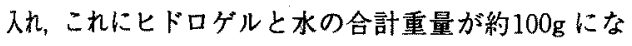
るように水を加え秤量した。試料管をモーターに取り付

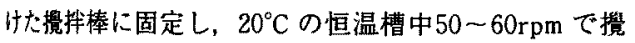
批した。その後，所定時間毎に浸漬水 $100 \mu \mathrm{l}$ ずつを採取 し，PEG 濃度を測定した。

\subsection{PEG 0 定量}

採取した浸漬水 $100 \mu \mathrm{l}$ をねじ口試料管に入れ，これに 臭化水素と酶酸の混合溶液 (1:1) $1 \mathrm{ml}$ を加えて密閉 し, $150^{\circ} \mathrm{C}$ の油浴に漬け， 3 時間反応させた。 $\left.+\mathrm{CH}_{2} \mathrm{CH}_{2} \mathrm{O}\right)_{\mathrm{n}} \longrightarrow \mathrm{nBrCH} \mathrm{CH}_{2} \mathrm{Br}+\mathrm{nH}_{2} \mathrm{O}$ $\mathrm{HBr}, \mathrm{AcOH}$

反庍終了後試験管を油浴から取り出し, 放冷した。こ れに水 $5 \mathrm{ml}$, 二硫化炭素 $500 \mu \mathrm{l}$ を加えて 1 分間振り混 ぜ, 1.2-ジブロモエタンを二硫化炭素中に抽出した。こ れを10分間遠心分蜼 $(1500 \mathrm{rpm})$ した後，下層の二硫化 崖素中の1.2-ジブロモエタンをガスクロマトクラフ （GC）で定量分析した。なお，用いた二硫化炭素には内 部嫩準物質として，1.2-ジブロモプロパンを加えておい た(浱度 $\left.18 \mu \mathrm{l} / 100 \mathrm{mlCS}_{2}\right)$ 。ジブロモエタンとジブロモ プバンの GC ピーク面積比を求め, あらかじめ濃度既 知の $\mathrm{PEG}(\mathrm{M}=2000)$ 水溶液を用いて作成しておいた検 量缐より PEGの濃度を求めた。なお，検量線作成用標 隻浚液としては PEG（M=2000） $0.1 \sim 0.2 \mathrm{~g} / 1$ の 6 種類

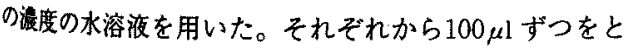

$\eta$ ，上記方法で反応させ， $\mathrm{CS}_{2}$ に抽出し，抽出度 $1 \mu 1$ をGCに注入した。ジプロモエタンとジブロモプロパン の面積比と PEG 水溶液濃度とをプロットすると直線関 係が得られ、これを検量線とした。

\subsection{PVA/トリオレイン系㲘化ヒドロゲルからの放出 オイルの定量}

2.3 で得た PVA/トリオレイン系ヒドロゲルを $100 \mathrm{ml}$ 試料管に入れ，水 $90 \mathrm{ml}$ を加之, 2.4 と同様の方法で $20^{\circ} \mathrm{C}$ で拍拌した。所定時間後, 浸㴖水を $500 \mathrm{ml}$ フラスコに入 れ，少量の水でヒドロゲルを洗浄し，その洗液もこれに 加えた。これに50mlのn一ヘキサンを加えて擋拌し， $\mathrm{n}^{-}$ ヘキサン層を分離した。この操作を 5 回絽り返し, 得ら れた抽出液を乾燥後, 減圧蒸留で溶媒を留去し, 重量を 測定した。

\section{3. 結果と考察}

PVA 凍結ゲルからの放出速度に対する凍結回数及び PEG の分子量の影響を図 $1 （ 1 ４ ） に$ 示した。凍結一 解凍の繰り返し回数の増加にしたがって放出速度が小さ くなり，また，PEGの分子量が大きいものほど放出速 度が小さかった。PEGを含まないPVA ヒドロゲルから の PVAの溶解性を調べたところ，PEGの放出量測定時 間 (35時間) 後で, 凍結回数 1 回のときPVAの溶解率 $9 \%$, 凍結回数 2 回以上でPVAの浴解率 $4 \%$ 以下であ った。徒って，図1で示したPEGの放出はPVA 担体の 溶解に伴うものではなく, PEG 自体の搪散によるもの と考えられる。また，PEGを含むPVA ヒドロゲルから の PVAの溶解率を測定したところ, 凍結回数 $3 \sim 7$ 回 で 2〜 4 \%であったので, PVAの溶解はPEGの存在に 影響されないことがわかった。時間 $\mathrm{t}(\mathrm{s})$ 後に界面を 通って浸漬水中に搪散するPEG の総量 Q $(\mathrm{g})$ は次式で 与えられる。

$$
\mathrm{Q}=\frac{\mathrm{ACo} \sqrt{\mathrm{Dt}}}{\sqrt{\pi}}
$$

ここで，A はゲルの表面積 $\left(\mathrm{cm}^{2}\right), \mathrm{Co}$ はゲル中の PEG の初濃度 $\left(\mathrm{g} / \mathrm{cm}^{3}\right)$, D は PEGのゲル中での搪散係数で ある。

図2（1－4）に示すように放出初期においてそれぞ れの PEG 分子量及び凍結回数における Q はすべて直線となる。放出初期においては表面積は一定 とみなせるので図 2 の傾きより求めた搪散係数 $\mathrm{D}$ と凍 結回数との関係を図 3 に示した。これよりいずれの PEG でも凍結回数が増すにつれて拡散係数は減少し, ある回数でほぼ一定になっており，その回数は $\mathrm{M}=$ 3000の場合を除いて分子量が大きいものほど小さくなっ ている。PEGの分子量と D の平衡値及び凍結回数 $\mathrm{N}=$ 


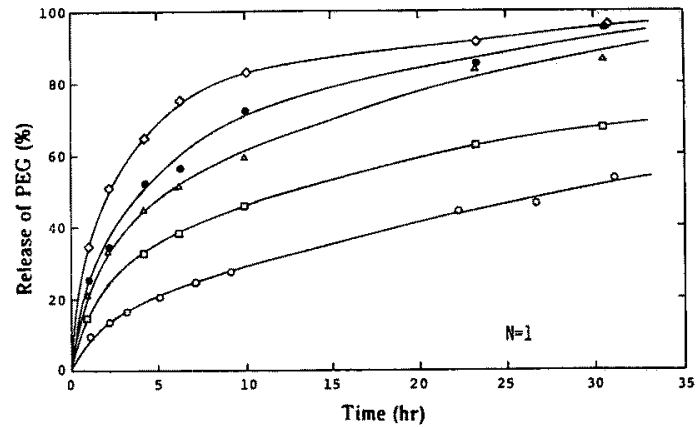

Fig. 1-1 Effects of PEG molecular weight for PEG release at $\mathrm{N}$ (freezing cycle number) $=1$ PEG average molecular weight $(\overline{\mathrm{M}})$ $\diamond: 200, \bigcirc: 600, \triangle: 1000, \square: 2000, \bigcirc: 3000$

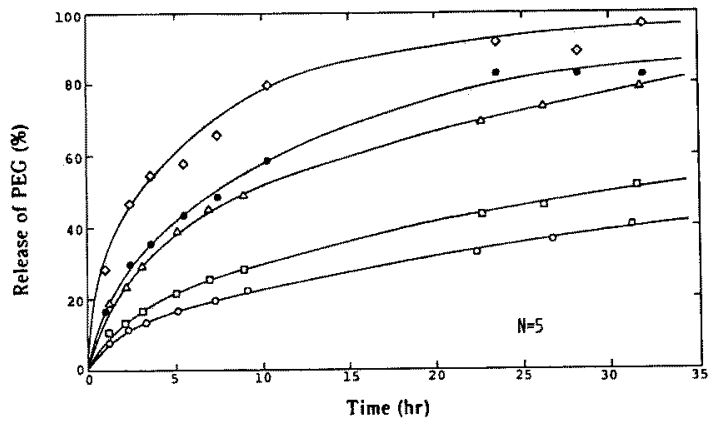

Fig. 1-2 Effects of PEG molecular weight for PEG re lease at $\mathrm{N}=5$

PEG average molecular weight $(\overline{\mathrm{M}})$

$\diamond: 200, \bigcirc: 600, \triangle: 1000, \square: 2000, \bigcirc: 3000$

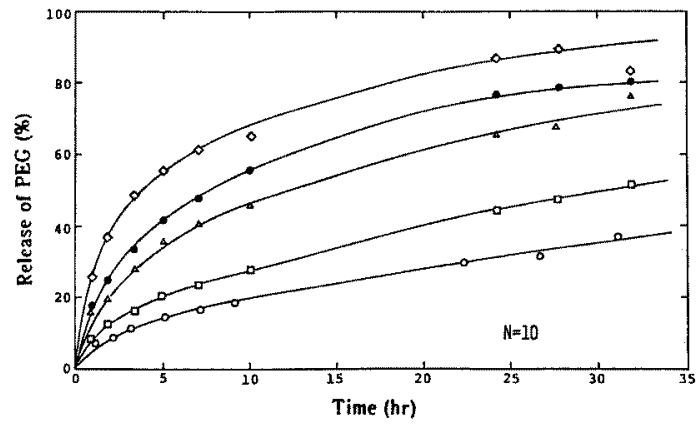

Fig. 1-3 Effects of PEG molecular weight for PEG release at $N=10$

PEG average molecular weight $(\overline{\mathrm{M}})$

$\diamond: 200,0: 600, \triangle: 1000, \square: 2000,0: 3000$

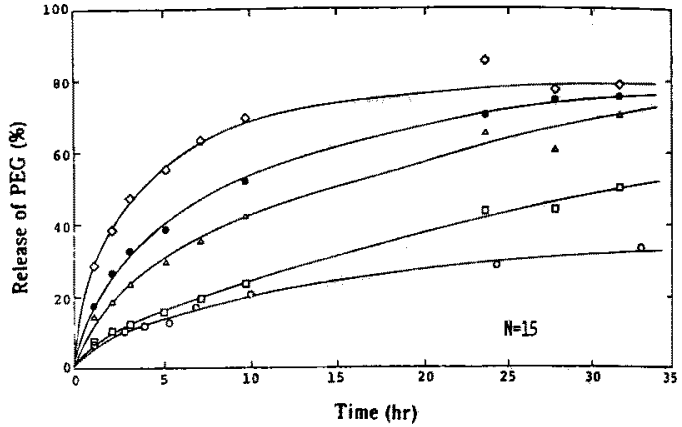

Fig. 1-4 Effects of PEG molecular weight for PEG release at $\mathrm{N}=15$

PEG average molecular weight $\bigcirc: 200, \bigcirc: 600, \triangle: 1000, \square: 2000,0: 3000$

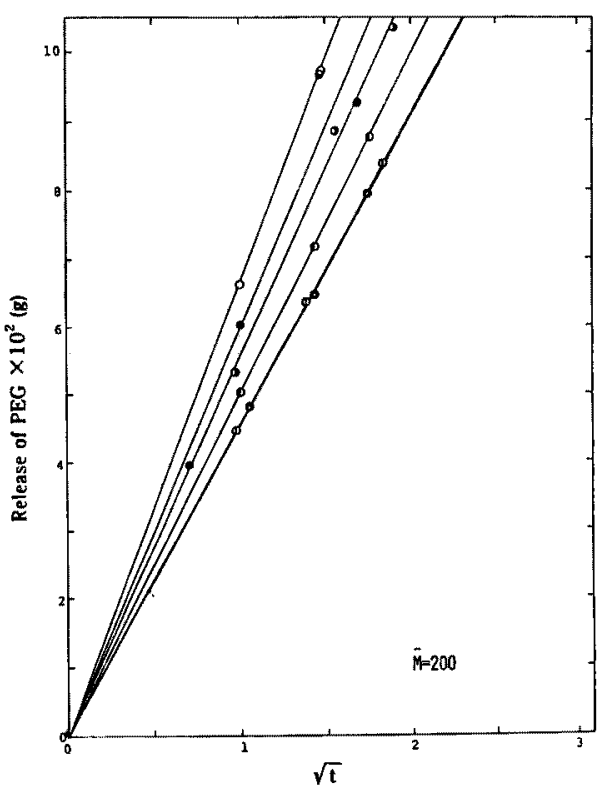

Fig. 2-1 Plots of PEG release vs. $\sqrt{t}$ at $\vec{M}=200$ Freezing cycle number $\bigcirc: 1, \bigcirc:(\mathcal{O}: 5, \mathcal{O}: 7, \mathbb{D}: 10, \bigcirc: 15$ 


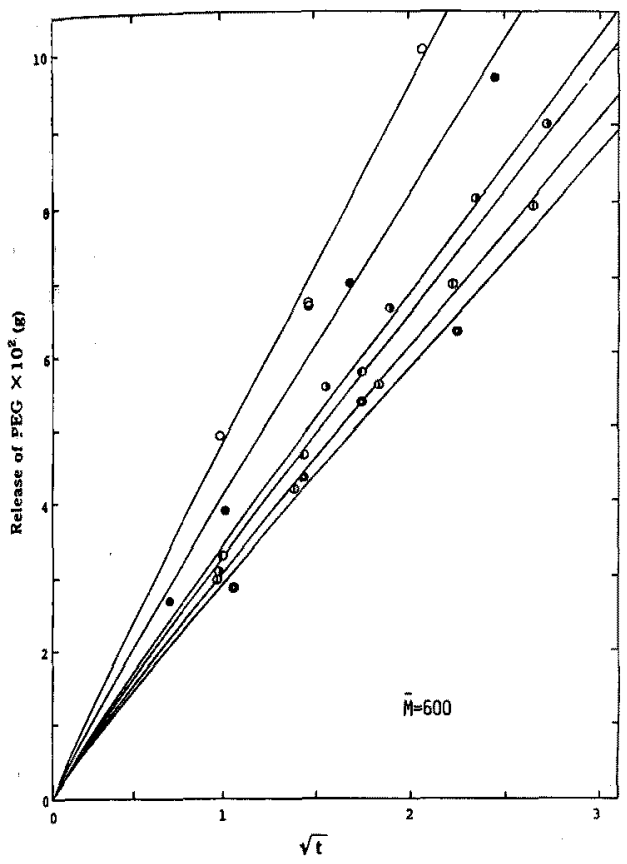

Fig. 2-2 Plots of PEG release vs. $\sqrt{t}$ at $\bar{M}=600$ Freezing cycle number

O:1, ๑:3, (:5, O:7, (1:10, O:15

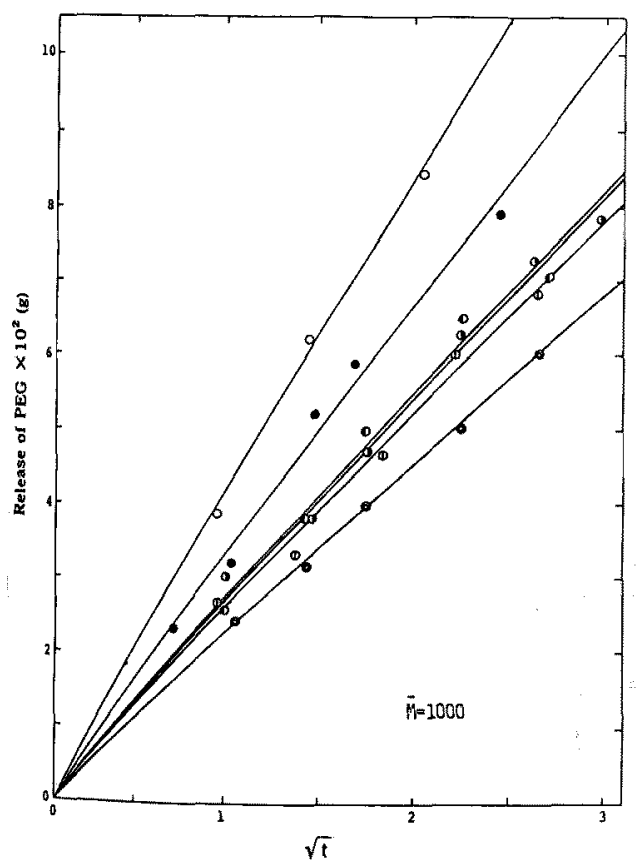

Fig. 2-3 Plots of PEG release vs. $\sqrt{t}$ at $\bar{M}=1000$ Freezing cycle number

O:1, ๑:3, ๑:5, ๑:7, (1:10, @:15

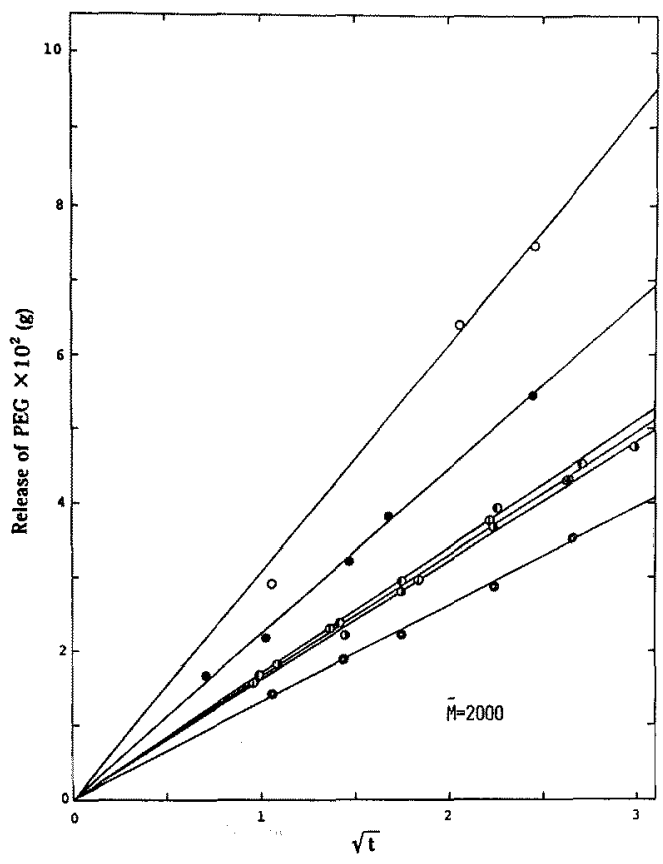

Fig. 2-4 Plots of PEG release vs. $\sqrt{t}$ at $\bar{M}=2000$ Freezing cycle number

O:1, ๑:3, (:5, (:7, (1:10, (0:15

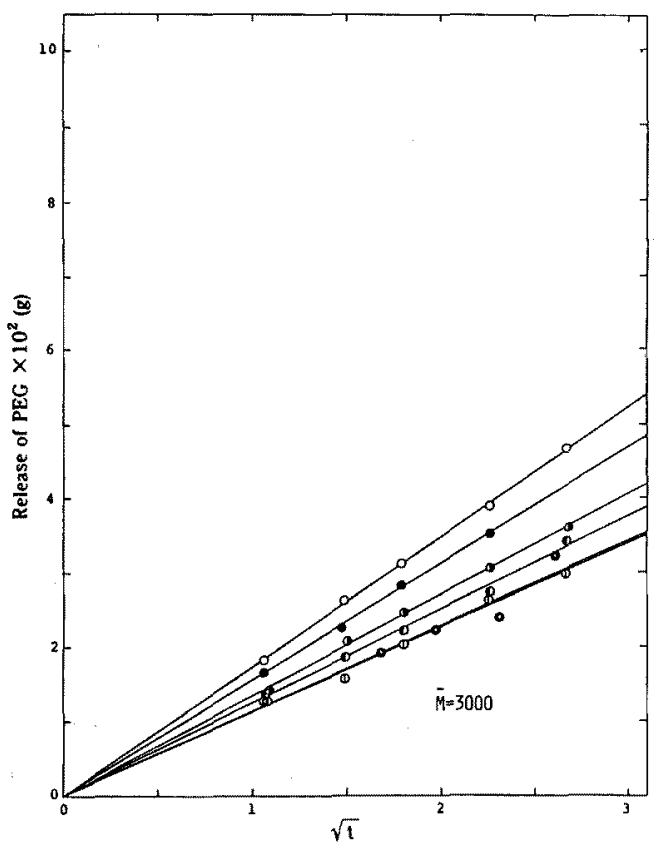

Fig. 2-5 Plots of PEG release vs. $\sqrt{t}$ at $M=3000$ Freezing cycle number

$\bigcirc: 1,0: 3,(5,0: 7,(1: 10,0: 15$ 


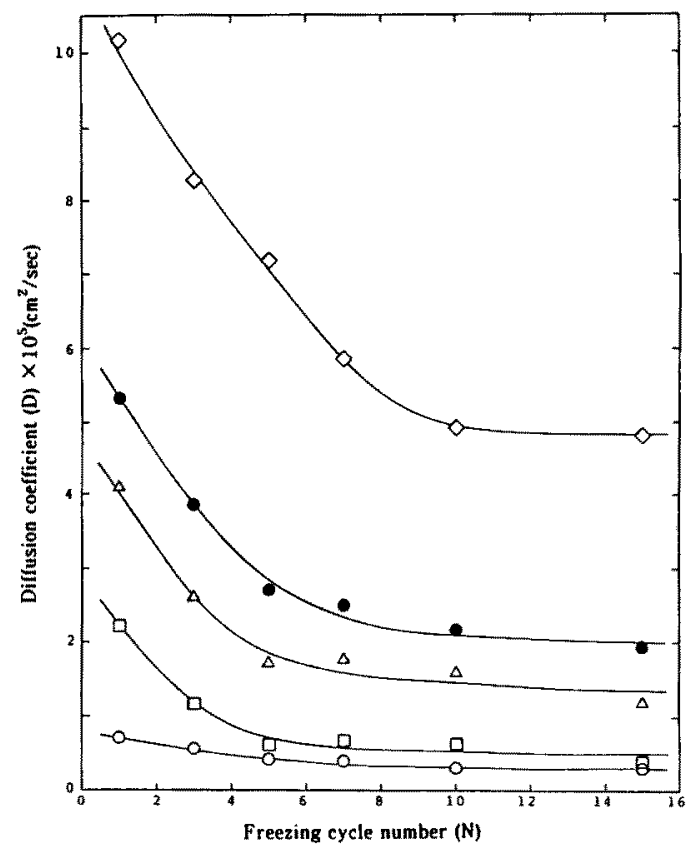

Fig. 3 Plots of diffusion coefficient (D) vs. N PEG average molecular weight $\bigcirc: 200, \bigcirc: 600, \triangle: 1000, \square: 2000,0: 3000$

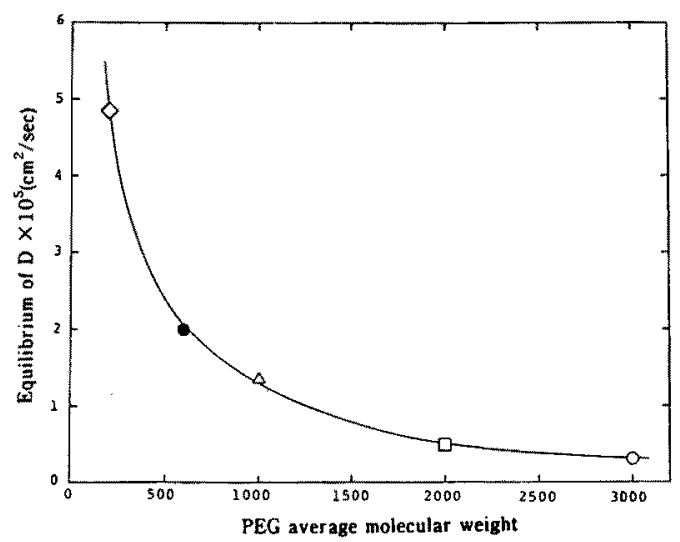

Fig. 4 Plots of D equilibrium vs. $\bar{M}$

1ー5における傾きとの関係をそれぞれ图4 と图 5 に示 した。图4よりPEGは分子量が䄪1000までは分子量が 增えるに従って拡散係数は急激に隇少し，その後ははば 一定となることがわかった。図 5 は PEGの分子量が小 さいほど凍結回数の影響を大きく受けることを示す。ま た，图５に扔いて PEG の分子量加3000をこえると200ー 2000の範囲で得られた直線からはずれてくるが，これは 溶液調製時にや、不透明であり，PVA/PEG/水の3成分
系において液夜相分離がゲル化が起ったためと思われ $3^{5) 6)}$ 。

PVA/トリオレイン系乳化ヒドロゲルにおけるトリオ レインの放出速度を罒6に示した。これよりトリオレイ ンはゲルに安定に包括されることが確認された。また， 凍結回数の増加による包括性の向上もみられだ。リオ レインがどのような状態でヒドロゲル中に取込まれてい るがは不明であるが，乳化した蹯水性洨体が安定にヒト ロゲルに包括されることがわかった。さらにこのような 安定な乳化ヒドロゲルの利用については今後検討してい きたい。

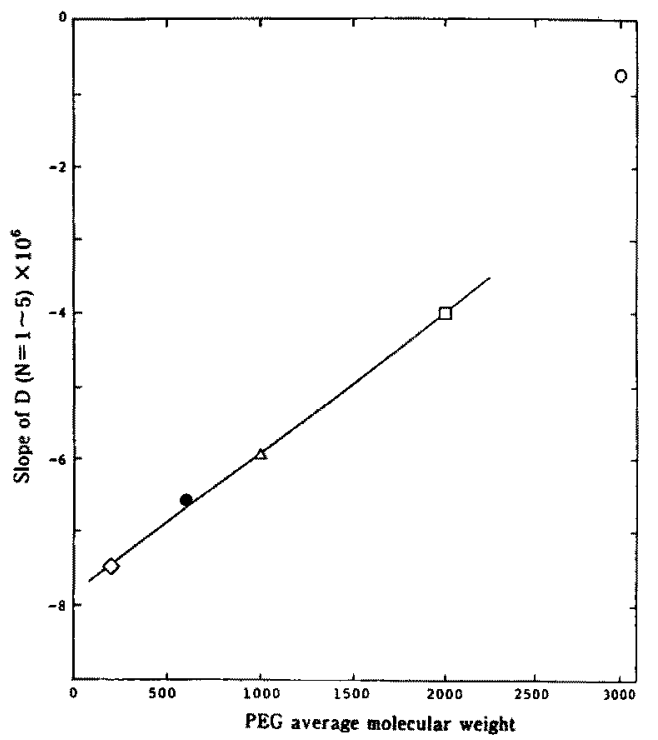

Fig. 5 Plots of D slope $(N=1 \sim 5)$ vs. $\bar{M}$

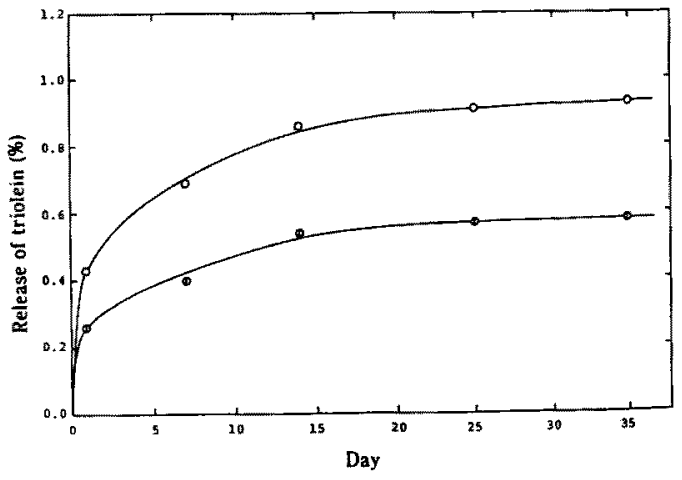

Fig. 6 Plots of triolein release vs. day Freezing cycle number $0: 1,0: 10$ 


\section{4. 結 言}

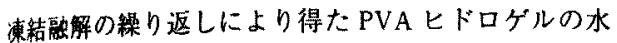
溶性高分子 PEG に对寸る包括性を調べた。PEGの放出 速度はPEGの分子量が大きいほど、また凍結反復回数 が增すにつれて荤くなった。放出時間と放出量との関係 より拉散保数 Dを近似的に求めることができた。。Dは 湅秙回数が增すにつれて娍少するが，ある回数以後はほ は一定となク，その回数は包接 PEGの分子量に依存 し，分子量が大きいほど少ない凍結回数でDは一定と なった。また，乳化したオイルを反復凍結解凍法で PVAヒドロゲルに包括すると極めて安定に包括できる ことがわかった。

\section{文献}

1）南部昌生，高分子加工， 32，523（1983）

同上，高分子，35，87 (1986)

2) M. Watase, K. Nishinari, M. Nanbu, Cryo. Lett., 4, 197 (1983)

3) F. Yokoyama et al., Colloid \& Polym. Sci., 264, 595 (1986)

4) 高村 彰, 新井基晴、石井文由, 薬学雑誌，107, 233 (1987)

5) I. Inamura et al., Polym. J., 16, 657 (1984)

6) I. Inamura, Polym. J., 18, 269 (1986) 